\title{
GÊNERO E VIOLÊNCIA NO ÂMBITO DOMÉSTICO: RELATO DE CASO
}

\section{GENDER AND DOMESTIC VIOLENCE IN THE RESIDENCE: A CASE REPORT}

\author{
Márcia Cançado Figueiredo ${ }^{1}$, Júlia Cristina Machado Viero ${ }^{2}$, Melina de Oliveira \\ Cesar $^{3}$, Juliana Plegge da Silva ${ }^{4}$, Elen Maria Bandeira Borba \\ ${ }^{1}$ Professora Associada IV da Faculdade de Odontologia da Universidade Federal do Rio \\ Grande do Sul, Porto Alegre, Brasil. Doutorado em Odontopediatria pela Faculdade de \\ Odontologia de Bauru Universidade de São Paulo - USP, Brasil, mcf1958@gmail.com \\ ${ }^{2}$ Acadêmica da Faculdade de Odontologia da Universidade Federal do Rio Grande do Sul - \\ UFRGS, Porto Alegre Brasil, jujuviero@hotmail.com \\ ${ }^{3}$ Acadêmica de semestre da Faculdade de Odontologia da Universidade Federal do Rio \\ Grande do Sul - UFRGS, Porto Alegre,Brasil, melinacesar@yahoo.com.br \\ ${ }_{4}^{4}$ Acadêmica da Faculdade de Odontologia da Universidade Federal do Rio Grande do Sul - \\ UFRGS, Porto Alegre,Brasil, juliplegge@gmail.com \\ ${ }^{5}$ Arquiteta sanitarista de Porto Alegre, RS - Brasil, elenmariabb@gmail.com
}

Data de recebimento: 08/04/2014

Data da aprovação: 10/05/2014

\section{RESUMO}

A violência contra a mulher geralmente tem sinais de ferimentos que são facilmente visíveis para os dentistas, os quais, por sua vez, têm a obrigação moral e legal de reconhecer e denunciar suspeitas de violência. O presente trabalho objetiva apresentar caso clínico de mulher que foi violentada no ambiente domiciliar, tornando-se uma paciente com deficiência, e auxiliar os cirurgiões-dentistas no sentido de que eles possam garantir ao sistema de justiça penal instrumentos necessários a fim de que os direitos dessas mulheres sejam exercidos. Os cirurgiões-dentistas, como outros profissionais da área da saúde, devem ser capazes de reconhecer os sinais de violência, discutirem suas preocupações com o paciente e saberem para onde encaminhar as vítimas a fim de que elas obtenham assistência. É um dever legal destes profissionais notificarem os casos a fim de interromper o ciclo de violência doméstica.

Palavras-chave: Violência contra a mulher. Violência doméstica. Pessoas com deficiência.

\begin{abstract}
Violence against women usually have signs of injuries that are easily visible to dentists. Dentists have a moral and legal obligation to recognize and report suspected violence. This study has the objective to present a case report of a woman who was raped in the home environment and to assist dentists in the sense that they can provide the criminal justice system tools needed to ensure that the rights of these women are transformed into reality. The dentists, like any other health professionals should be able to recognize signs of violence, to discuss their concerns with the patient and to know where to refer the victims to ensure that those get assistance. It is a legal duty of these professionals to notify cases in order to intempt the cycle of domestic violence.
\end{abstract}

Keywords: Violence against women. Domestic violence. People with disabilities. 


\section{INTRODUÇÃO}

A violência contra a mulher não conhece fronteiras e infringe os direitos humanos. Segundo a doutora Helene Gayle, presidente da CARE (Cooperative for Assistance and Relief Everywhere Inc.) - organização humanitária internacional de combate à pobreza que ajuda a capacitar meninas e mulheres marginalizadas -, a violência contra mulheres e meninas é uma das muitas causas da miséria, sendo essa uma violação dos direitos humanos e uma barreira para resolver desafios globais, como o combate ou controle ao vírus HIV (DELAHUNT et al., 2010).

A violência contra a mulher provoca muito mais dor do que marcas visíveis de feridas e cicatrizes. Atos de agressão física, abuso psicológico, coerção sexual, vários comportamentos controladores, tais como isolar uma pessoa de sua família, são considerados como violência doméstica (ZOLOTOR; DENAHM; WEIL,2009).

Esse tipo de violência de gênero encontrase em proporções epidêmicas em muitos dos países mais pobres do mundo. Segundo Ki-Moon (2007), uma a cada três mulheres é espancada, coagida ao sexo ou abusada de outra forma durante sua vida. Essa taxa chega a atingir o índice alarmante de $70 \%$ da população feminina em alguns países do mundo (DELAHUNT et al., 2010).Um relatório recente do governo queniano revela mais de 12.500 casos de meninas que foram abusadas sexualmente por professores ao longo de um período de 5 anos apesar de esse número parecer de grande magnitude, devemos observar que o problema deve ser ainda maior devido às subnotificações (Enotes.com, 2011). No Brasil, esses índices também são aterradores. Segundo Dias, o Relatório Nacional Brasileiro retrata o perfil da mulher brasileira e refere que a cada 15 segundos uma mulher é agredida, totalizando, em 24 horas, um número de 5.760 mulheres espancadas no Brasil (DIAS, 2010). No Estado do Rio Grande do Sul, segundo dados da polícia, somente do mês de janeiro a abril de 2012, 86 mulheres foram mortas, sendo que 30 tiveram o próprio companheiro como algoz (ALMEIDA, 2012).

Todavia casos de violência contra mulheres não ocorrem apenas em países subdesenvolvidos, mas, com efeito, são reportados em escala mundial.
A não punição pelo sistema judiciário também não é ocorrência comum apenas em países pobres; há diversos casos relatados na mídia em que o agressor ficou impune pelos seus atos. Exemplo disso que teve muita repercussão na mídia internacional foi o caso do ex-atleta O.J. Simpson, que matou sua ex-mulher, Nicole Brown, e um amigo dela a facadas. O.J. foi acusado pelo assassinato, porém não foi condenado e acabou sendo absolvido pelo júri. Denise Brown, irmã de Nicole, dedicou-se à causa de erradicar a violência doméstica. Ela relata em sua página pessoal que quatro mulheres morrem por dia nas mãos de alguém que amam e/ou acreditam poder confiar. $\mathrm{E}$ as crianças que vivem nos lares em que há esse tipo de violação dos direitos humanos geralmente sofrem severas sequelas (problemas cognitivos ou de linguagem, atraso no desenvolvimento, doenças relacionadas ao estresse físico), além de grande parte também sofrer abusos ou negligência.

Segundo a Juíza Andréa Pachá, em artigo escrito para o Portal Conselho Nacional de Justiça: "A violência de gênero se mantém, não discrimina classe social, grau de escolaridade, renda ou idade, é uma violência silenciosa, que afronta a dignidade individual e corrói os valores e a estrutura das famílias".

A Síndrome das Mulheres Maltratadas (BWS) foi relatada pela primeira vez ao público por Walker, uma psicóloga americana, em meados dos anos 1970. Ela descreveu padrões de sintomas psicológicos e comportamentais da vítima de agressão (Enotes.com, 2011). É muito comum a agredida ignorar e negar sistematicamente os desmandos e os atropelos sofridos pelo companheiro, tendo extrema dificuldade de romper com a relação violenta e denunciar o agressor. Mulheres que foram física, emocional ou sexualmente agredidas, durante muitos anos podem perder toda a autoconfiança e autorrespeito. Walker ainda observou a presença de um ciclo de espancamento padrão, cujo conceito é composto basicamente por três partes: 1) "Construção de tensão no relacionamento": podem ocorrer incidentes menores (agressões verbais, por exemplo). A mulher costuma se sentir responsável pelos atos do companheiro e geralmente age tentando acalmar seu agressor. 2) "Fase de explosão": é quando ocorrem as agressões agudas. A relação se torna inadiministrável e tudo se transforma em descontrole e destruição. 3) "Lua de mel" - quando ocorre o autoengano. $\mathrm{O}$ agressor é observado como um ser 
amoroso e generoso, demonstrando-se com remorso pelo seu ato de violência, levando a companheira a perdoá-lo. (Family Crisis Center, 2010)

Segundo Deslandes, os reflexos da violência são nitidamente percebidos no âmbito dos serviços de saúde, seja pelos custos que representam, seja pela complexidade do atendimento que demandam. Dessa maneira, esse setor tem importante papel no enfrentamento da violência familiar. Todavia, os profissionais dessa área tendem a subestimar a importância do fenômeno, voltando suas atenções às lesões físicas, raramente se empenhando em prevenir ou diagnosticar a origem das injúrias. (DESLANDES,1999). Esse fato pode estar relacionado à falta de preparo profissional, ou, simplesmente, à decisão de não se envolver com os casos.

Em razão de $65 \%$ das lesões de abuso envolverem área de cabeça, pescoço ou boca, o profissional da odontologia está em uma boa posição para observá-las. (MCDOWELL; KASSEBAUM; STONGBOE,1992) Os cirurgiões-dentistas, como prestadores de cuidados de saúde primários, têm por obrigação moral, bem como legal, de notificar os casos de abusos às autoridades competentes (SALIBA et al.,2007).

Alguns dados estatísticos encontrados a partir de inquéritos realizados em ambiente hospitalar são as seguintes: 20 a $30 \%$ das mulheres têm sido fisicamente / sexualmente abusadas em um relacionamento anterior ou vigente; no caso dos homens, o índice é de 7,5\%. Os $33 \%$ dos homicídios do sexo feminino são o resultado de disputas domésticas. Os 94\% das vítimas de violência por parceiro íntimo têm traumatismos do pescoço e da cabeça. Os $81 \%$ das vítimas tinham traumas máxilofaciais. (WHO, 2005; GIRO et al, 2004).

\section{OBJETIVO}

Este trabalho tem como finalidade apresentar um relato de caso clínico de uma mulher vítima de violência domiciliar, auxiliando os cirurgiões-dentistas no sentido de que eles possam garantir para o sistema de justiça penal instrumentos necessários para que os direitos de mulheres, vítimas de violência doméstica, sejam transformados em realidade.

\section{MATERIAIS E MÉTODO}

Este trabalho é de caráter descritivo, tendo enfoque no caso clínico, com uma abordagem qualitati- va a fim de analisar questões subjetivas, relacionadas aos sentimentos vividos pela paciente.

O caso a ser relatado é de uma paciente que se tornou portadora de necessidades especiais após sofrer sucessivos episódios de violência doméstica com diferentes parceiros. Ela procurou em janeiro de 2012 o atendimento odontológico na Faculdade de Odontologia da Universidade Federal do Rio Grande do Sul, especificamente na disciplina de Atendimento Odontológico do Paciente com Necessidades Especiais.

A coleta de dados foi fundamentada a partir de uma versão reduzida do questionário original "Instrumento da OMS sobre violência contra a mulher" (2005), em que constam avaliações da violência em todos seus aspectos e tipos. ${ }^{18}$ Análise do processo clínico da paciente; observação, avaliação e diálogo com a entrevistada; conhecimentos científicos aprendidos anteriormente; método descritivo; e pesquisa bibliográfica também foram utilizados para composição do trabalho.

A entrevista com a paciente ocorreu em uma sala do andar térreo do Centro de Saúde Santa Marta, pertencente à Secretaria Municipal de Saúde de Porto Alegre, localizado no centro de Porto Alegre, por ser local de fácil acesso, escolhido pela paciente, devido a sua dificuldade de locomoção.

O projeto foi submetido à apreciação do Comitê de Ética em Pesquisa da Faculdade de Odontologia da Universidade Federal do Rio Grande do Sul e aprovado sob o número 21988, datado de 12 de dezembro de 2011, e no Comitê de Ética em Pesquisa da Secretaria Municipal de Saúde de Porto Alegre, sob o registro do CEP 638 em 17 de junho de 2011.

Antes da entrevista, a paciente foi informada do objetivo do estudo e assinou termo de consentimento livre e esclarecido autorizando a utilização de suas respostas e imagens para a confecção deste trabalho.

\section{RESULTADOS}

A paciente S.R.G.S, gênero feminino, solteira, 45 anos, $1^{\circ}$ grau incompleto, três filhos, moradora da cidade de Viamão (RS), procurou atendimento na Faculdade de Odontologia da Universidade Federal do Rio Grande do Sul, na disciplina de Atendimento Odontológico a Pacientes Portadores de Necessidades Especiais no ano de 2011. Ela é portadora de paraplegia espástica secundária (CID10) 
devido à trauma raquimedular (Figura 1). Essa lesão foi causada quando a paciente tinha 22 anos de idade, consequência de uma facada que levou de seu ex-marido há 23 anos (Figura 2). De acordo com o laudo médico, solicitado pela referida disciplina para iniciar o tratamento odontológico da paciente, ela necessitava de cuidados especiais devido ao nível da lesão medular (acima de T6), que provocava distúrbios autonômicos.

Figura 1- Paciente S.R.G.S, portadora de paraplegia espástica secundária (CID10)

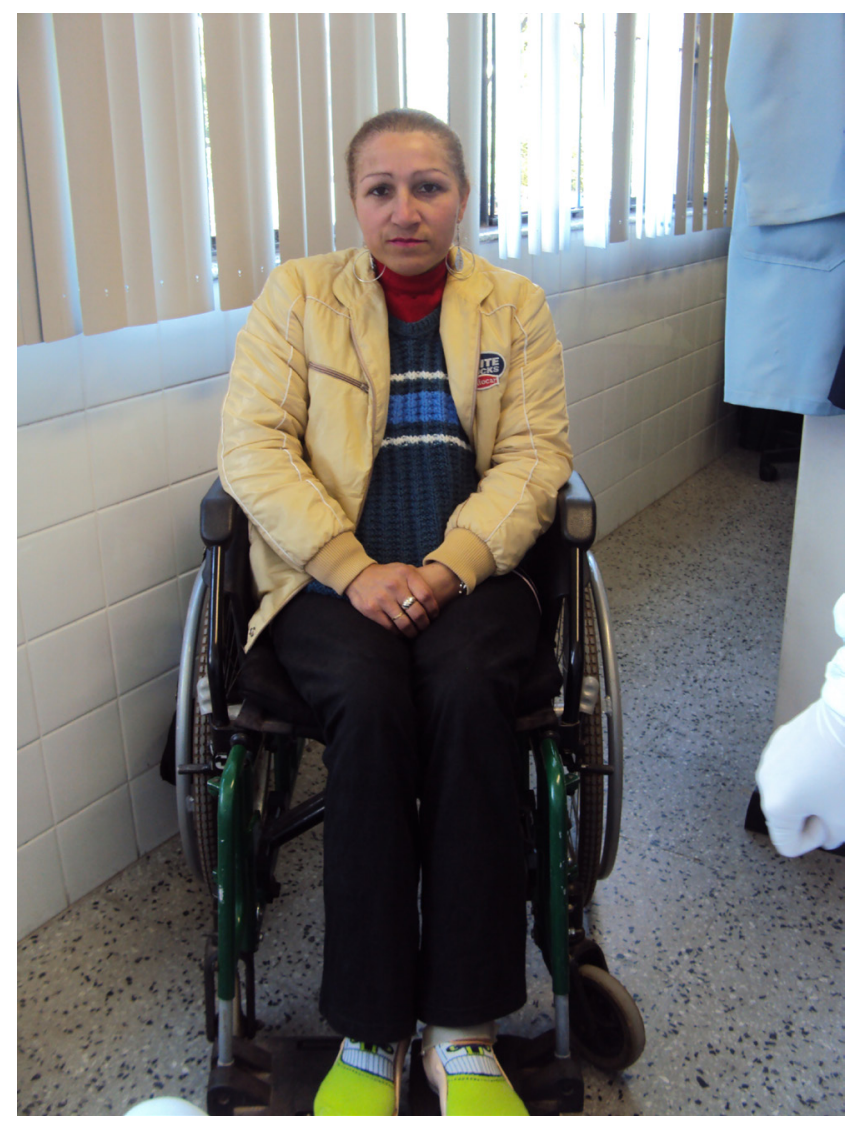

Figura 2 - A cicatriz de uma facada que levou de seu exmarido há 23 anos

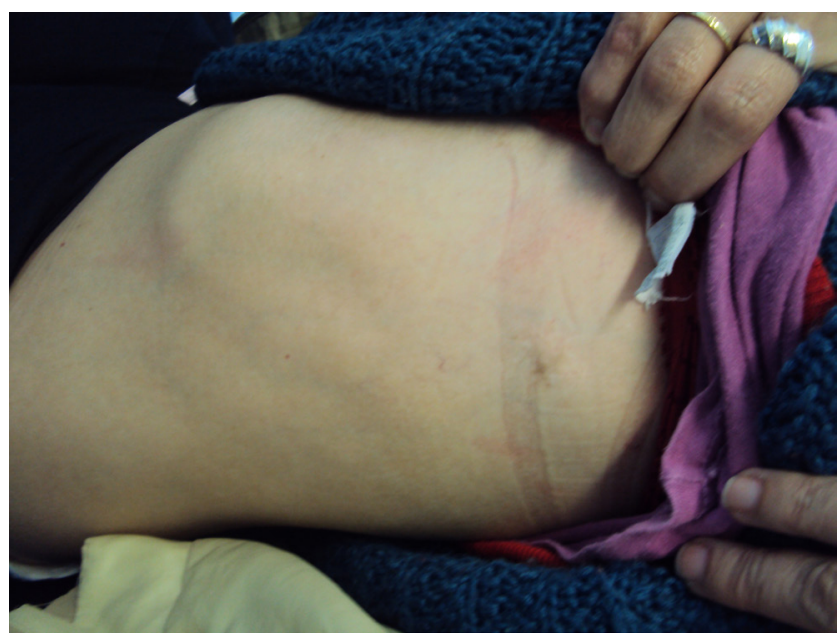

Os profissionais da área da saúde devem estar atentos aos cuidados necessários durante o atendimento aos pacientes com lesão medular para a prevenção da espasticidade (gerada pela hiperatividade medular reflexa), o que leva a paciente estudada a fazer uso diário de $10 \mathrm{mg}$ do fármaco antispástico de ação medular, denominado Baclofen. Além disso, apresenta bexiga neurogênica, que provoca seu incompleto esvaziamento, promovendo aumento de infecções urinárias.

A S.R.G.S, quando chegou à faculdade, apresentava muitas necessidades odontológicas: dentes cariados $(11,12,22,25,26,36,46,47)$, restos radiculares $(24,37)$ e cálculo na região ântero-inferior. Queixava-se também de sintomatologia dolorosa principalmente na região dos molares inferiores do lado esquerdo e direito, fato justificado por Giro et al .(2004), que relataram que muitas vezes o acesso de pacientes com necessidades especiais aos cuidados de saúde bucal é limitado, tanto pela própria incapacidade em identificar a causa como de avaliar corretamente sua condição bucal. Segundo esses mesmos autores, a prevenção é uma estratégia fundamental a ser utilizada, principalmente por meio da orientação e educação dessas pessoas ou de seus cuidadores.

No caso da paciente em questão, o tratamento necessário foi fundamentalmente curativo (exodontias, endodontia, restaurações, tartarectomia e instrução de higiene oral), realizado de março a dezembro de 2011, sem qualquer intercorrência médica e odontológica. Atualmente, ela encontra-se em controle, 
devendo retornar a cada seis meses para manutenção odontológica periódica na referida disciplina.

\section{DISCUSSÃO}

O caso desta paciente chamou muito a atenção dos profissionais envolvidos em seu tratamento, não pelo aspecto clínico odontológico em si, mas pelos relatos de antecedentes familiares, em que ela se colocou como vítima de violência doméstica.

Muitas questões importantes vieram à tona quanto à questão de pacientes violentados e foi identificada a necessidade de se realizar uma capacitação de como lidar com uma paciente vítima de violência doméstica. Segundo Corrêa (2002), um dos aspectos mais inquietantes do tratamento odontológico aos pacientes portadores de distúrbios neuropsicomotores é a relação que se estabelece entre o cirurgião-dentista e o paciente, portanto a anamnese apresenta um papel fundamental dentro da abordagem odontológica.

Deste modo, torna-se importante ressaltar aqui que é fundamental o profissional da saúde que saiba conduzir a entrevista dialogada. Foi a partir dessa entrevista que se soube das agressões que a paciente havia sofrido e o motivo pelo qual ela era paraplégica. Os cirurgiões-dentistas têm um papel social que vai muito além dos cuidados com a cavidade oral; esses profissionais devem ser promotores da saúde tanto física como mental de seus pacientes.

Para a delegada Márcia Salgado (2005), maior que o medo da reação do companheiro é a vergonha. Como as agressões acontecem na esfera privada, para denunciar é preciso que a vítima devasse sua vida publicamente. $\mathrm{O}$ referido caso não foi diferente. A paciente relatou não ter tido coragem de denunciar seu marido na época, porque teria vergonha de "falar mal e continuar casada com ele" e "mantinha-se com ele por causa de seus três filhos, mesmo com os episódios recorrentes de agressão que ela sofria, tanto as físicas como as verbais".

Segundo o trabalho realizado pelo Instituto Avon/IPSOS em 2011, dentre as respostas estimuladas, as duas principais razões para uma mulher permanecer nesse tipo de relação são: falta de condições econômicas para se sustentar $(27 \%)$ e falta de condições para criar os filhos $(20 \%)$. Chama a atenção neste quadro o fato de que $17 \%$ das mulheres brasileiras citam o medo de ser morta como principal razão para uma mulher agredida continuar em uma relação abusiva.

A paciente relatou que apenas saiu de sua moradia em que vivia com seu primeiro marido após a situação ficar insustentável e as agressões cada vez mais frequentes. Assim, decidiu ir para a casa de sua mãe, com os três filhos, e foi lá que recebeu a facada que a tornou uma cadeirante.

Em nosso país, as mulheres estão protegidas pela lei 11.340/2006, que é relativamente recente, sancionada pelo Presidente da República Luis Inácio Lula da Silva, na data de 07 de agosto de 2006. A lei também ficou conhecida como Maria da Penha em homenagem a Maria da Penha Maia Fernandes, que igualmente ficou paraplégica por causa de torturas aplicadas por seu marido em 1983. Os envolvidos no processo (polícia, promotoria, magistratura) demoraram 19 anos para condenar o responsável a apenas dois anos de prisão. A Comissão e a Corte Interamericana de Direitos Humanos deram uma resposta no caso $\mathrm{n}^{\circ}$ 12.051/OEA e obrigaram o Brasil a aprovar a lei 11.340, com base no caso Maria da Penha. Desde então, devem ser denunciados os casos individuais de violação dos direitos das mulheres e também os representantes dos poderes públicos que protegem esses abusos.

O ocorrido com S.R.G.S foi muito assemelhado ao caso de Maria da Penha, que serviu de paradigma para a sanção da lei de proteção à mulher. A semelhança das histórias de vida de ambas não se deu apenas por essas duas mulheres terem se tornadas paraplégicas por agressões de seus maridos, mas também pela desatenção ou até mesmo descaso do poder público brasileiro frente aos casos de violência contra mulheres e a grande demora em tomar providências adequadas. Apesar de ter sido realizado um boletim de ocorrência quando S.R.G.S foi internada no hospital logo após a facada, essa relatou que não teve conhecimento de medidas legais que tenham sido tomadas contra o agressor, que até hoje continua impune.

Infelizmente, na época em que S.R.G.S sofreu as agressões, a Lei de Proteção à Mulher não havia sido ainda sancionada, pois com a regulamentação dessa houveram grandes mudanças no julgamento dos casos. Observamos que após sua sanção foram criados juizados especiais de violência doméstica e familiar contra a mulher com competência cível e criminal para abranger todas as questões; a violência 
contra a mulher passou a ser categorizada em física, psicológica, sexual, patrimonial e moral; a lei prevê um capítulo específico para o atendimento pela autoridade policial para os casos de violência domestica contra a mulher; a pena de crime de violência doméstica passou a ser de 3 meses a 3 anos (anteriormente era de 1 mês a 1 ano, sendo que alguns casos apenas aplicavam penas pecuniárias como doações de cestas básicas e multa); entre várias outras medidas que asseguraram os direitos das mulheres. Segundo Jacobucci (2004), a impunidade após a prática de crime atentatório à vida de mulheres, mesmo havendo evidências literárias demonstrando os índices catastróficos de que a violência doméstica e o estupro superam todos os tipos de câncer, acidentes de trânsito, guerras, e são considerados a sexta causa de anos de vida perdidos por morte ou incapacidade física em mulheres, vitimizando inclusive suas testemunhas emocionalmente e seus espectadores moralmente, as autoridades, muitas vezes, demonstram-se inertes.

Passados dezesseis anos de sua experiência traumática com seu primeiro relacionamento, durante seu tratamento fisioterápico, a paciente S. R. G. S. conheceu seu segundo companheiro, que era deficiente físico e que também passou a agredi-la física e verbalmente. Porém dessa vez foi diferente; apesar de no momento inicial a paciente permanecer passiva a tal situação, segundo ela por "medo de ficar sozinha", tomou coragem e, com o auxílio de uma amiga, o denunciou em uma delegacia de mulheres. Segundo Souza, os motivos que mantêm as mulheres inseridas nos contextos do relacionamento violento são: a convivência com o medo, a dependência financeira e a submissão, até o momento em que decidem realizar a denúncia e passam por cima do sentimento de pena do marido, do tempo de vida juntos e da anulação durante o relacionamento. O medo de ficar sozinha foi elencado também como um dos motivos para a manutenção de uma relação desse tipo.

Stavrianos et al (2011) relataram que é difícil para a mulher conseguir sair sozinha de uma relação tão complexa, na qual é vítima de violência conjugal. Há necessidade de que alguém a escute de forma verdadeira e sem julgamentos. Segundo os mesmos autores, a busca por auxílio para cessar as agressões pode, algumas vezes, ser de grande importância, assim como a intervenção da família do agressor, a ajuda do profissional da saúde, do psicoterapeuta, do ad- vogado, de um líder religioso ou de centros de ajuda comunitária, como a delegacia da mulher, clínicas de instituições de ensino, centros de apoio às vítimas de violência, entre outros.

Para Stavrianos et al. (2011), dentre os profissionais da área de saúde, destaca-se o cirurgiãodentista, que deve prestar auxílio nessa tarefa de orientar uma vítima a denunciar seu agressor. Todavia ainda é muito grande o desconhecimento dos mesmos sobre o assunto violência doméstica. Este foi um fato também observado no desenvolvimento da apresentação deste caso clínico, em que se procurou na literatura informações de que os cirurgiõesdentistas podem garantir para o sistema de justiça penal, instrumentos necessários a fim de que os direitos destas mulheres sejam transformados em realidade.

A mulher vítima de violência deverá, para sua proteção e de seus familiares, comparecer sozinha ou acompanhada de pessoas de sua confiança a uma delegacia comum ou à Delegacia de Atendimento Especializado à Mulher (DEAM) mais próxima e relatar a ocorrência dos fatos para efetuar o registro do Boletim de Ocorrência contra seu agressor. A própria delegacia entrará com um processo no Ministério Publico e/ou Foro da Vara da Família e Criminal, para que o agressor seja intimado e/ou preso. Se houver testemunhas do ato, elas devem ser apresentadas ou mencionadas.

A vítima também pode entrar em contato gratuitamente e com garantia de ser preservada sua identidade com a Central de Atendimento à Mulher. A Central criada em 2005 funciona 24h todos os dias da semana e tem como objetivo receber relatos de violência contra as mulheres, acolher e orientá-las em situação de violência doméstica e familiar, assim como divulgar serviços disponíveis na rede de atendimento à mulher em todo o território nacional. Para tal atendimento, basta ligar 180 .

Terceiros também podem registrar ocorrências nos casos de violência física e sexual. Os profissionais da saúde, como já dito anteriormente, têm a obrigação legal de notificar tais casos, e se esse dever não for cumprido, está prevista penalidade por inobservância de tais obrigações que são estabelecidas por lei. Quando a vítima de violência comparecer a algum setor de saúde, tal como hospital ou unidade básica de saúde (UBS), durante o atendimento, os profissionais 
deverão estar atentos, fazer as perguntas referentes ao que está acontecendo e, mesmo que a vítima informe não ter acontecido coisa alguma, esse profissional deverá fazer a notificação por meio do SINAN (Sistema de Informação de Agravos de Notificação), instrumento oficial de notificação de casos suspeitos e confirmados de violências, utilizado pelos serviços de saúde dos municípios brasileiros. Essa será enviada para os órgãos competentes, como a Coordenação Geral de Vigilância em Saúde (CGVS) do município, setor de notificação de violência, que entrará em contato com a paciente e seus familiares e fará o encaminhamento devido, que pode ser o deslocamento dela com seus filhos para um abrigo, um encaminhamento para um emprego e creche para seus filhos, quando menores, na segurança total dela e de seus familiares.

O Código de Ética Odontológica apresenta como dever dos profissionais o zelo pela saúde e pela dignidade de seus pacientes. Logo, a observância do dever moral de proteger seu paciente é fundamental para um bom exercício da profissão. Ressaltando que, como já referenciado anteriormente, o cirurgiãodentista é um dos profissionais da saúde com maiores chances de detectar violência doméstica, principalmente a física, por ser a face o local preferencial das lesões (SALIBA et al.2007).

De acordo com Deslandes, Gomes e Silva em 2000, no que se refere ao atendimento a mulheres vítimas de violência que procuraram o serviço de emergência em hospitais, o dentista foi o segundo profissional mais solicitado, ficando atrás apenas do médico ortopedista.

Figueiredo et al (2012) buscaram conhecer a prevalência de mulheres vítimas de violência por meio dos casos notificados no período de 2009 e 2010 por meio do SINAN, e confirmaram que, dos 1278 casos notificados, a contusão foi a natureza da lesão mais constatada, tendo a cabeça e a face como os locais mais prevalentes para as agressões.

Esses autores verificaram que $73,4 \%$ das mulheres tiveram o encaminhamento para $\mathrm{o}$ atendimento ambulatorial no setor saúde e, nos demais setores, foram encaminhados para o Conselho Tutelar (73,16\%) e Instituto Médico Legal (41,54\%). Analisando esse tipo de encaminhamento no setor de saúde, os casos ambulatoriais (73,4\%) foram expressivamente superiores à internação hospitalar $(12,5 \%)$. Isso se deve ao fato de que a grande maioria dos casos foi de contusão, em que o trauma ocorreu em tecidos moles, causando principalmente edema e hematoma. Jaramillo e Uribe (2001) também relataram que, no atendimento clínico voltado às mulheres violentadas, foram frequentes as contusões, lacerações e fraturas. Para Schraiber (2002), a preferência do agressor pela região da face é porque essa região caracteriza um ato de grande humilhação, além de tornar a lesão visível, ferindo a beleza feminina e sua relação com a sociedade.

É para isso que existem medidas que protegem as vítimas de seu agressor, visando assegurar a proteção física e psicológica à mulher e a seus dependentes. Algumas delas são o afastamento do agressor do domicílio e a proibição de sua aproximação física junto à mulher agredida e aos filhos. A vítima pode buscar ajuda em serviços que mantêm casas-abrigo (moradias em local secreto, onde a mulher e os filhos não podem ser encontrados pelo agressor). Dependendo do tipo de crime de que foi vítima, a mulher pode precisar de um advogado, e o Estado pode nomear um para defendê-la. (LUNGARZO, 2010; AGUIAR, 2002).

Finalizando, no trabalho de Figueiredo et al (2012), os registros de ocorrência do SINAN, no município de Porto Alegre, não apresentaram qualquer caso de traumatismo dentário notificado tendo a face como a parte do corpo mais atingida. Por essa razão, os autores reforçaram que o papel do cirurgião-dentista é incontestável e de extrema relevância, tanto no diagnóstico dos casos como no tratamento, orientação, notificação e encaminhamento das mulheres vítima de violência.

Espera-se, com a publicação deste trabalho, facilitar a notificação/informação de violência doméstica, que são fundamentos importantes para o planejamento e a execução de ações voltadas para redução da morbimortalidade decorrente das violências e para a promoção da educação em saúde.

\section{CONCLUSÃO}

Casos de violência doméstica possuem grande prevalência em nossa sociedade. Os cirurgiões-dentistas, como os outros profissionais da área da saúde, devem ser capazes de reconhecer os sinais de violência, discutir suas preocupações com o paciente e saber para onde encaminhar as vítimas 
a fim de que elas obtenham assistência. É um dever legal desses profissionais notificarem os casos a fim de interromper o ciclo de violência doméstica.

\section{AGRADECIMENTOS}

Os autores agradecem a coordenadora de saúde bucal do município de Viamão, Rio Grande do Sul, dra. Virginia Espina, pelo apoio dado à paciente, possibilitando assim que seu tratamento odontológico fosse realizado em outro município.

\section{REFERÊNCIAS}

AGUIAR, C. (Coord.). Guia de serviços de atenção a pessoas em situação de violência. Salvador: Fórum Comunitário de Combate a Violência/ Grupo de Trabalho Rede de Atenção; 2002. Disponível em: <http://www.dhnet. org.br/dados/guias/a_pdf/guia_sit_violencia_ba.pdf $>$. Acesso em: setembro 2012.

ALMEIDA, K. Mulheres assasinadas. Zero Hora, 27 maio 2012. Seção: Polícia.

BROWN, D. Making a difference one day at time! United States, 2011. Disponível em: <http://www.denisebrown. com/speaking.htm>. Acesso em: set. 2011.

CORRÊA, N. S. M. P. Atendimento odontopediátrico: aspectos psicológicos. São Paulo. Santos; 2002. p.29-534

DELAHUNT, B., POE, T., KERRY, J., SNOWE, O., BOXER, B.; COLLINS, S. CARE celebrates introduction of International Violence Against Women Act (IVAWA). 2010. Disponível em: <http://www.care.org/ newsroom/articles/2010/02/care-celebrates-introductionof-international-violence-against-women-act-20100208. asp>. Acesso em: mar. 2013.

DESLANDES, S. F. O atendimento às vítimas de violência na emergência: "prevenção numa hora dessas?". Rev C S Col. , v.4, n.1, p. 81-94, 1999.

DESLANDES, S. F., GOMES, R., SILVA, C. M. F. P. Caracterização dos casos de violência doméstica contra a mulher atendidos em dois hospitais públicos do Rio de Janeiro. Cad Saúde Pública, v.16, p.129-37, 2000.

DESLANDES, S. F; PAIXÃO, A. C. W. Humanização da assistência às vítimas de abuso sexual infantil: retomando o debate sobre a relação médico-paciente. In: DESLANDES, S. F. Humanização dos cuidados em saúde: conceitos, dilemas e práticas. Rio de Janeiro: Fiocruz; 2006. p.301-20.

DIAS, M.B. A impunidade dos delitos domésticos. Palestra proferida no Congresso Nacional da Associação Brasileira das Mulheres de Carreira Jurídica, 10. Maceió, Alagoas, 27/10/2010. Disponível em: <www.mariaberenice.com. br>. Acesso em: out. 2012.
ENOTES.com. Violence against women: introduction. 2011. Disponível em: <http://www.enotes.com/violenceagainst-article>. Acesso em: jan. 2013.

FAMILY CRISIS CENTER. Building brighter tomorrows. United States; 2010. Adapted from Leonore Walker, The battered woman adapted. New York: Harper and How, 1979 Disponível em: <http://www.1736familycrisiscenter.org/pdf/ Cycle\%20of\%20Violence_v3.pdf $>$. Acesso em: mar. 2013.

FIGUEIREDO, M. C., CESAR, M. O; SILVA, J. P.; BORBA, B. E. M. Prevalência de mulheres vítimas de violência no município de Porto Alegre e a influência de suas variáveis no âmbito odontológico. Rfo UPF, v.17, n.3, p.254-260, 2012.

GIRO, E. M. A.; ORRICO, S. R. P.; CAMPOS, J. A. D. B.; LORENA, S. M. ;CORTEZ, L. M. S. Prevalência de cárie em pacientes com necessidades especiais institucionalizados ou não-institucionalizados: consumo de carboidratos simples. Rev. Odontol. UNESP. v.33, n.2, p.75-9, 2004.

INSTITUTO AVON. Percepções sobre a violência doméstica contra a mulher no Brasil. 2011. Disponível em: <http://www.institutoavon.org.br/wpcontent/themes/ institutoavon/pdf/iavon_0109_pesq_portuga_vd2010_03_ vl_bx.pdf $>$. Acesso em: mar. 2012.

JACOBUCCI, P., CABRAL, A. Depressão e traços de personalidade em mulheres vítimas de violência doméstica. Rev Bras de Psiquiatr. v.26, n.3, 2004.

JARAMILLO, D. E., URIBE, T. M. Rol del personal en la atención a las mujeres maltratadas. Invest. Educ. Enferm., v.19, n.1, p.38-45, 2001.

KI-MOON, B. Violence against women: facts and figures. 2007. Disponível em: <http://www.unifem.org/attachments/ gender_issues/violence_against_women/facts_figures_ violence_against_women_2007.pdf $>$. Acesso em: jul. 2011.

LE, B. T., DIERKS, E. J., UEECK, B. A., HOMER, L. D.,POTTER, B. F. Maxillofacial injuries associated with domestic violence. J Oral Maxillofac Surg., v.59, n.11, p.1277-83, 2001.

LUNGARZO, C. Um caso de violência doméstica contra mulher (Apelo de ação solidária). 2010. Disponível em: <http://www.consciencia.net/um-caso-de-violenciadomestica-contra-mulher-apelo-de-acao-solidaria-2/> Acesso em: out. 2012].

MCDOWELL, J. D.; KASSEBAUM, D. K. ;STONGBOE, S. E. Recognizing and reporting victims of domestic violence. J Am Dent Assoc. 1992. 123; 44-50

NICOLE BROWN FOUNDATION. Knowledge is power. United States; 2011. Disponível em: <http://www. nicolebrown.org/get_help.html> Acesso em: set. 2011. 
PACHÁ, A. Igualdade em construção. Portal do Conselho Nacional de Justiça. 2008. Disponível em: <http://www. cnj.jus.br/imprensa/artigos/13324-igualdade-em-constru>. Acesso em: jan. 2012.

PETROBRÁS. Combate à violência contra a mulher : respeitar a mulher: essa é a lei. 2011. Disponível em: $<$ http://www.sepm.gov.br/subsecretaria-de-enfrentamentoa-violencia-contra-as-mulheres/lei-maria-da-penha/ cartilhabr-mulher09.pdf $>$ Acesso em: mar. 2013.

SALGADO, M. Pressão familiar e vergonha atrasam denúncias de violência doméstica. 2005. Disponível em: $\quad<$ http://www1.folha.uol.com.br/folha/cotidiano/ ult95u106524.shtml>. Acesso em: dez. 2012.

SALIBA, O., GARBIN, C., GARBIN, A., DOSSI, A. Responsabilidade do profissional de saúde sobre a notificação de casos de violência doméstica. Rev Saúde Públ., v.41, n.3, 2007.

SCHRAIBER, L. B., D'OLIVEIRA, A. F. P. L., FRANÇA JUNIOR, I., PINHO, A. A. Violência contra a mulher: estudo em uma unidade de atenção primária à saúde. Rev Saúde Pública v.36, n.1, p.470-7, 2002.

SECRETARIA DE POLÍTICAS PARA AS MULHERES. Lei Maria da Penha coíbe violência doméstica e familiar contra a mulher. 2011. Disponível em: <http://www.sepm. gov.br/publicacoes-teste/publicacoes/2011/LMP-2011\%20 com $\%$ 20nova 180\%20e\%20selo\%205\%20anos\%20LMP. pdf>. Acesso em: mar. 2013.

SECRETARIA NACIONAL SOBRE A MULHER TRABAlHADORA DA CUT. A Lei Maria da Penha: uma nova conquista - novos desafios. 2007. Disponível em: $<$ http://andif.com.br/img/pdf/Lei_Maria_da_Penha.pdf $>$. Acesso em: jul. 2013.

SOUZA, P.; DA ROS, M. A. Os motivos que mantêm as mulheres vítimas de violência no relacionamento violento. Rev Cien Hum. v.40, p.509-27, 2006.

STAVRIANOS, C., VASILIADIS, L., PAPADOPOULOS, C., PANTELIDOU, O., PANTAZIS, A. E., KONOSIDOU, N. Violence against women: case report.. Research Journal of Medical Sciences.; v.5, n.3, p.122-125, 2011. Doi: 10.3923/rjmsci.2011.122.125

SUJATHA, G; SIVAKUMAR, G.; SARASWATHI, T. R. Role of a dentist in discrimination of abuse from accident. J Forensic Dent Sci., Jan, v.2, n.1, p.2-4 2010. Doi: 10.4103/0974-2948.71049.

ZOLOTOR, A., DENAHM, A., WEIL, A. Intimate partner violence. Obstet Gynecol Clin North Am. Dec, v.36, n.4, p.847-60, 2009. Doi: 10.1016/j.ogc.2009.10.011.
WORLD HEALTH ORGANIZATION (WHO).Multicountry study on women's health and domestic violence against women. Geneva; 2005. Disponível em: <http:// apps.who.int/iris/bitstream/10665/43309/1/924159358X_ eng.pdf?ua=1>. Acesso em: mar. 2013. 